https://helda.helsinki.fi

Child-perceived teacher emotional support, its relations with teaching practices, and task persistence

Kikas, Eve

2019-04

Kikas , E \& Tang , X 2019 , ' Child-perceived teacher emotional support, its relations with teaching practices, and task persistence ' , European Journal of Psychology of Education , vol. 34 , no. 2 , pp. 359-374 . https://doi.org/10.1007/s10212-018-0392-y

http://hdl.handle.net/10138/324882

https://doi.org/10.1007/s10212-018-0392-y

draft

Downloaded from Helda, University of Helsinki institutional repository.

This is an electronic reprint of the original article.

This reprint may differ from the original in pagination and typographic detail.

Please cite the original version. 


\section{Dear Author}

Here are the proofs of your article.

- You can submit your corrections online, via e-mail or by fax.

- For online submission please insert your corrections in the online correction form. Always indicate the line number to which the correction refers.

- You can also insert your corrections in the proof PDF and email the annotated PDF.

- For fax submission, please ensure that your corrections are clearly legible. Use a fine black pen and write the correction in the margin, not too close to the edge of the page.

- Remember to note the journal title, article number, and your name when sending your response via e-mail or fax.

- Check the metadata sheet to make sure that the header information, especially author names and the corresponding affiliations are correctly shown.

- Check the questions that may have arisen during copy editing and insert your answers/corrections.

- Check that the text is complete and that all figures, tables and their legends are included. Also check the accuracy of special characters, equations, and electronic supplementary material if applicable. If necessary refer to the Edited manuscript.

- The publication of inaccurate data such as dosages and units can have serious consequences. Please take particular care that all such details are correct.

- Please do not make changes that involve only matters of style. We have generally introduced forms that follow the journal's style.

- Substantial changes in content, e.g., new results, corrected values, title and authorship are not allowed without the approval of the responsible editor. In such a case, please contact the Editorial Office and return his/her consent together with the proof.

- If we do not receive your corrections within 48 hours, we will send you a reminder.

- Your article will be published Online First approximately one week after receipt of your corrected proofs. This is the official first publication citable with the DOI. Further changes are, therefore, not possible.

- The printed version will follow in a forthcoming issue.

\section{Please note}

After online publication, subscribers (personal/institutional) to this journal will have access to the complete article via the DOI using the URL:

http://dx.doi.org/10.1007/s10212-018-0392-y

If you would like to know when your article has been published online, take advantage of our free alert service. For registration and further information, go to:

http://www.link.springer.com.

Due to the electronic nature of the procedure, the manuscript and the original figures will only be returned to you on special request. When you return your corrections, please inform us, if you would like to have these documents returned. 


\section{Metadata of the article that will be visualized in OnlineFirst}

1 Article Title Child-perceived teacher emotional support, its relations with teaching practices, and task persistence

2 Article Sub- Title

3 Article Copyright - Instituto Superior de Psicologia Aplicada, Lisboa, Portugal and Year Springer Nature B.V. 2018

(This will be the copyright line in the final PDF)

4 Journal Name European Journal of Psychology of Education

5 Family Name Kikas

6 Particle

7

8 Corresponding Suffix

9 Author Organization Tallinn University

10 Division School of Natural Sciences and Health

11 Address Narva mnt 25, Tallinn 10120

12 e-mail eve.kikas@tlu.ee

13 Family Name Tang

14 Particle

$15 \quad$ Given Name Xin

16 Suffix

17 Author Organization University of Helsinki

18 Division Department of Educational Science

19 Address $\quad$ PL 9 (Siltavuorenpenger 5A), Helsinki 00014

20 e-mail xin.tang@helsinki.fi

$21 \quad$ Received 22 February 2018

22 Schedule $\quad$ Revised April 2018

$23 \quad$ Accepted 8 June 2018

24 Abstract This study examined relations between child-reported teacher emotional support, teaching practices, and children's task-persistent learning behaviour. The study was carried out in Estonia, where a students' first teacher advances with his/her students and teaches all primary subjects in the first 3 years of schooling. In total, 660 sixth-grade children reported about their first teacher's emotional support. Teachers' child-centred and teacher-directed practices were observed with the Early Childhood Classroom Observation Measure (ECCOM); results included 38 teachers in Grade 1, and 37 in Grade 3. Within the same grades, teachers reported on their affection for students, as well as their behavioural and psychological control over students. Teachers also 
evaluated each of their student's task persistence. As shown by ECCOM results, retrospective student-reported teacher emotional support tended to be positively related to child-centred practises, and negatively related to teacherdirected practises in Grade 3, while also negatively related to teacher-reported psychological control in Grade 1. Although higher perceived emotional support was related with more persistent learning behaviour on an individual level, general task persistence was predicted primarily by teacher-reported practices at the classroom level.

25 Keywords separated by ' - '

26 Foot note information
Teacher emotional support - Child perception - Child-centred and teacherdirected teaching practices - Teacher affection - Behavioural control Psychological control

Eve Kikas. School of Natural Sciences and Health, Tallinn University, Narva mnt. 25, 10120 Tallinn, Estonia; Email: eve.kikas@tlu.ee Current themes of research:

Children's development and learning in kindergarten and school. The role of individual characteristics and contextual factors (e.g. teaching practices, parental support) in students' learning, considering varying skill levels and ages.

Most relevant publications in the field of Psychology of Education:

Peets, K., \& Kikas, E. (2017). Teachers' promotion or inhibition of children's aggression depends on peer-group characteristics. Journal of Clinical Child \& Adolescent Psychology, 46, 848-857. DOI: https://doi.org/10.1080 /15374416.2015.1079778

Kikas, E., Pakarinen, E., Soodla, P., Peets, K., \& Lerkkanen, M.-K. (2017). Associations between reading skills, interest in reading, and teaching practices in first grade. Scandinavian Journal of Educational Research. DOI:https://doi.org/10.1080/00313831.2017.1307272

Kikas, E., Silinskas, G., Jõgi, A.-L., \& Soodla, P. (2016). Effects of teacher's individualized support on children's reading skills and interest in classrooms with different teaching styles. Learning and Individual Differences, 49, 270-277. Doi: https://doi.org/10.1016/j.lindif.2016.05.015

Kikas, E., \& Mägi, K. (2016). Does self-efficacy mediate the effect of primary school teachers' emotional support on learning behavior and academic skills? Journal of Early Adolescence, 37, 696-730. doi: https://doi.org/10.1177 /0272431615624567

Kikas, E., Silinskas, G., and Soodla, P. (2015). The effects of children's reading skills and interest on teacher perceptions of children's skills and ndividualized support. International Journal of Behavioral Development, 39, 402-412. DOI: https://doi.org/10.1177/0165025415573641.

Kikas, E., Peets, K., and Hodges, E. (2014). Collective student characteristics alter the effects of teaching practices on academic outcomes. Journal of Applied Developmental Psychology, 35, 273-283.

Kikas, E. (2004). Teachers' conceptions and misconceptions concerning three natural phenomena. Journal of Research in Science Teaching, 41, 432-448.

Xin Tang. Department of Educational Science, University of Helsinki, Finland; E-mail: xin.tang@helsinki.fi

Current themes of research:

Teaching practices. Reading development. Motivation and engagement. Most relevant publications in the field of Psychology of Education:

Tang, X., Pakarinen, E., Lerkkanen, M.-K., Kikas, E., Muotka, J., \& Nurmi, J.-E. (2017). Validating the early childhood classroom observation measure in first and third grade classrooms. Scandinavian Journal of Educational Research, 
61, 275-294.

Tang, X., Kikas, E., Pakarinen, E., Lerkkanen, M.-K., Muotka, J., \& Nurmi, J.-E. (2017). Profiles of teaching practices and reading skills at the first and third grade in Finland and Estonia. Teaching and Teacher Education, 64, 150-161. 


\title{
Child-perceived teacher emotional support, its relations with teaching practices, and task persistence
}

\author{
Eve Kikas ${ }^{1} \cdot$ Xin Tang $^{2}$
}

Abstract This study examined relations between child-reported teacher emotional support, teaching practices, and children's task-persistent learning behaviour. The study was carried out in Estonia, where a students' first teacher advances with his/her students and teaches all primary subjects in the first 3 years of schooling. In total, 660 sixth-grade children reported about their first teacher's emotional support. Teachers' child-centred and teacher-directed practices were observed with the Early Childhood Classroom Observation Measure (ECCOM); results included 38 teachers in Grade 1, and 37 in Grade 3. Within the same grades, teachers reported on their affection for students, as well as their behavioural and psychological control over students. Teachers also evaluated each of their student's task persistence. As shown by ECCOM results, retrospective student-reported teacher emotional support tended to be positively related to child-centred practises, and negatively related to teacher-directed practises in Grade 3, while also negatively related to teacher-reported psychological control in Grade 1. Although higher perceived emotional support was related with more persistent learning behaviour on an individual level, general task persistence was predicted primarily by teacher-reported practices at the classroom level.

Keywords Teacher emotional support · Child perception · Child-centred and teacher-directed teaching practices $\cdot$ Teacher affection $\cdot$ Behavioural control $\cdot$ Psychological control

Eve Kikas

eve.kikas@tlu.ee

Xin Tang

xin.tang@helsinki.fi

School of Natural Sciences and Health, Tallinn University, Narva mnt 25, 10120 Tallinn, Estonia

2 Department of Educational Science, University of Helsinki, PL 9 (Siltavuorenpenger 5A), 00014 Helsinki, Finland 


\section{Introduction}

Students' perceived teacher behaviours, such as teacher's emotional support, have been found to influence their learning motivation, behaviour, and academic outcomes (Patrick, Kaplan and Ryan 2007; Roorda, Koomen, Spilt and Oort 2011). However, each student perceives his/her teacher's behaviour from both the teacher's whole-class practices as well as individual interactions. Thus, it is of importance to examine the relationships between students' perceived teacher behaviour and teacher's teaching practices measured by observation and self-reports, and to analyse their joint influences on students' learning. The knowledge of these relations provides validity for assessments of teaching practices and is of practical importance for teachers to acknowledge students' different viewpoints. Therefore, the present study aims to examine the relationships between child-perceived teacher emotional support (Authors 2016a; Patrick et al. 2007), observed child-centred, and teacher-directed practices (see Childhood Classroom Observation Measure ECCOM; Stipek and Byler 2004), and teacher-reported affection, behavioural, and psychological control (see Kiuru et al. 2012). Moreover, in order to examine the unique role on learning behaviour, children's task-persistent learning behaviour was investigated by including all three measures of teaching jointly.

\section{Teacher's emotional support}

Teachers who show high emotional support are warm and kind, engage in positive and respectful communication with children, are sensitive to children's needs and interests, provide children with appropriate levels of autonomy, and help them feel comfortable in the classroom (Hamre and Pianta 2010). Students perceive emotional support as liking and caring expressed by a teacher, and this encourages students to invest in learning and follow teacher's instructions (Patrick et al. 2007). Promoting mutual respect and interaction among students supports students' feelings of belonging and autonomy (cf. Deci and Ryan 2000) and thus promotes learning engagement (Patrick, Kaplan and Ryan 2011).

Each student perceives teacher behaviour differently primarily due to objective reasonsteachers differ in general teaching practices and in their individualised support (e.g. Göllner, Wagner, Eccles and Trautwein 2017; Hamre and Pianta 2010). In addition, student perceptions differ because students differ in their previous experiences and beliefs (see Bandura1993; Grolnick, Ryan and Deci1991). Although each child perceives emotional support differently, teacher general practices may still differ such that students in one class generally perceive teacher support differently from students in another class. In several studies, teacher emotional support has been studied at the classroom level both through observations (Pianta et al. 2008) and via teacher reports (Archambault, Pagani, and Fitzpatrick 2013; Curby, Rimm-Kaufman and Ponitz 2009). These studies have also shown the benefits of higher general teacher emotional support to children's adaptive learning behaviour and academic achievement (e.g. Archambault et al. 2013; Curby et al. 2009). Thus far, the relations among general teaching practices and student-perceived emotional support have been under-examined. One study examined the relationships between students' reported teaching practices and observed teaching practices via the Classroom Assessment Scoring System (CLASS) that directly measures classroom-level emotional support besides instructional support and classroom organisation. This study showed that student reports, aggregated at the classroom level, were not very reliable to assess teacher practices (Downer, Stuhlman, Schweig, Martinez and Ruzek 2016). 
Child-perceived teacher emotional support, its relations with teaching...

\section{Observed and reported teaching practices and emotional support}

In the present study, a widely used observational tool, ECCOM, was utilised to assess two dimensions of child-centred and teacher-directed practices (Stipek and Byler 2004). These practices differ in the type of teacher and student activities, or in the degree to which teachers allow children to actively construct their knowledge. Child-centred teaching practices emphasise the active knowledge construction process, include children in various discipline-related decision processes, and create a positive social climate via individual support and encouragement of peer interactions (Authors 2014; McCombs 2010; Stipek and Byler 2004; Woolfolk Hoy and Weinstein 2011). In contrast, teacher-directed practices are characterised by teacher dominance and control, wherein students are regarded as passive 'receivers' (Gettinger and Kohler 2011; Woolfolk Hoy and Weinstein 2011). Thus, teachers individually encourage and emotionally support children primarily through child-centred, not teacher-directed practices. A study in kindergarten confirmed that the highest child-centred and lowest teacher-directed practices as evaluated by ECCOM were related to a medium-to-high score of Emotional Support as evaluated by CLASS (Salminen et al. 2012).

Moreover, in ECCOM, each dimension consists of and is measured by three subscales: management, instruction, and climate (Stipek and Byler 2004; Authors 2017a). Management relates to child responsibility, choice of activities, disciplinary strategies, and instructions for academically related activities. Instruction encompasses learning standards, coherence of instructional activities, instructional conversation, and academic subjects like literacy and math. Climate consists of items dealing with support for communication and interpersonal skills, student engagement, and individualization of learning activities; thus, is also related to emotional support. So far, there have been no studies with subscales, but it may be expected that emotional support is more apparent in climate subscales than in general scores.

Besides observed teaching, another way of measuring teaching practices is through teacher self-reports. One framework of teacher self-reported teaching in the classroom research has departed from parenting studies (Barber 1996; Baumrind 1967) to examine teacher-reported affection (responsiveness), behavioural, and psychological control (Dever and Karabenick 2011; Kiuru et al. 2012; Authors 2016b; Walker 2008). Affection refers to the extent to which adults show affective warmth, acceptance, and involvement. Behavioural control refers to attempts to direct a child by way of limits and demands. Psychological control refers to attempts to control the child's thinking and emotions through psychological means, such as withdrawal of affection, shaming, and induction of guilt. Thus, high emotional support is related both with high affection and low psychological control.

\section{Emotional support, teaching practices, and task persistence}

Empirical research has confirmed that perceived emotional support is associated with student engagement, achievements, and self-regulation (Klem and Connell 2004; Patrick et al. 2007; Skinner and Belmont 1993). One of the indicators of engagement is persistence in completing school tasks. High task persistence is characterised by demonstrating effort and not giving up easily in the face of challenges or difficult tasks, while low task persistence is characterised by a tendency to quit when faced with complicated tasks (Zhang, Nurmi, Kiuru, Lerkkanen and Aunola 2011; Yen, Konold and McDermott 2004). Authors (2016a) showed that students' retrospectively examined first-grade teachers' emotional support was related to children's task persistence and reading skills in Grade 6. Teacher's emotional support was related to higher 
self-concept in reading, and mediated the effect of emotional support on task persistence and reading skills.

Many studies have confirmed that child-centred practices are mostly beneficial, and teacher-directed practices mostly detrimental, for motivation and learning behaviour, including task persistence (Authors 2014, 2018; Lerkkanen et al. 2012; Perry, Donohue and Weinstein 2007; Turner et al. 2002). Research has also demonstrated the detrimental effect of psychological control on students' development (Barber 1996; Soenens, Sierens, Vansteenkiste, Dochy and Goossens 2012; Soenens and Vansteenkiste 2010). Specifically, psychological control has been found to relate to adverse outcomes through a lack of satisfying basic psychological needs (e.g. Assor, Kaplan, Kanat-Maymon and Roth 2005; van der KaapDeeder, Vansteenkiste, Soenens and Mabbe 2017).

\section{Aims and hypotheses}

The main aim of this study was to examine relations between child-reported teacher's emotional support and teaching practices. An additional aim was to study the joint effect of perceived emotional support and teaching practices on children's task-persistent learning behaviour. Child-centred and teacher-directed teaching practices were observed, and affection, behavioural, and psychological control examined with teacher reports in Grades 1 and 3. Child-perceived emotional control of the first classroom teacher was assessed retrospectively in Grade 6 (see also Authors 2016a). Retrospective reports were used because researchers have been rather cautious about using opinions from students who are still in primary school (Roorda et al. 2011). The design of the study was possible due to the specifics of the educational system in Estonia, where a single classroom teacher is responsible for all primary subjects in the first three grades of schooling. Students were therefore asked about this teacher's emotional support. The hypotheses were as follows.

First, it was predicted that more frequent usage of child-centred and less frequent usage of teacher-directed teaching practices would be positively related to students' retrospectively assessed perceived emotional support, both in Grade 1 and Grade 3. Namely, the creation of a positive social climate as well as supporting and encouraging students forms a part of childcentred, but not teacher-directed practices (Authors 2014; McCombs 2010; Stipek and Byler 2004; Woolfolk Hoy and Weinstein 2011). As students may better remember teacher practices at a later time, relations were expected to be higher for observations in Grade 3 than in Grade 1. And as the climate subscale specifically taps emotional support, it was expected that relations would be higher for this subscale than for the whole scale.

Second, it was expected that higher teacher affection and lower psychological control would be related to higher perceived emotional support. Affection includes showing warmth and acceptance, while psychological control includes withdrawal of affection, shaming, and induction of guilt (Baumrind 1967; Dever and Karabenick 2011; Kiuru et al. 2012; Walker 2008). High affection and low psychological control also tend to create conditions that satisfy basic psychological needs (Assor et al. 2005; van der Kaap-Deeder et al. 2017).

Third, it was hypothesised that higher perceived emotional support is related to higher task persistence on an individual level. Respect and care from a teacher supports students' feelings of belonging and autonomy (Deci and Ryan 2000) and support engagement and persistence in completing tasks (Patrick et al. 2011).

Fourth, it was expected that perceived emotional support - together with higher childcentred (as compared with teacher-directed) practices, teacher-reported affection, behavioural 
Child-perceived teacher emotional support, its relations with teaching...

control, and lower psychological control - together predict students' task persistence at the classroom level (cf. Authors 2014; Lerkkanen et al. 2012; Patrick et al. 2011; Soenens et al. 2012; Turner et al. 2002).

\section{Method}

\section{Sample and procedure}

The study sample came from 53 different classrooms in a larger longitudinal study 'Kindergarten-School Study' (see Authors 2014). In April-May of Grade 6, students were asked to complete a questionnaire concerning their first teacher's support. (In the Estonian school system, the first teacher advances with their students from Grade 1 until Grade 3, teaching the same group of students for 3 years.) In total, 660 students ( 333 boys; 327 girls) reported on their first teacher's emotional support.

The same first teachers were observed throughout February-March in Grade 1 and Grade 3. In Grade 1, 38 teachers were observed, while in Grade 3, 37 teachers were observed. Teachers were observed by two trained observers throughout three subsequent lessons in a single school day. In April-May for Grade 1 and Grade 3, teachers were asked about their teaching practices and about students' task-persistent learning behaviour. In Grade 1, 47 teachers completed the questionnaires, while in Grade 3, 50 teachers completed the questionnaires. Teachers' mean age was 42.28 years $(\mathrm{SD}=10.11)$, and their average work experience was 19.56 years $(\mathrm{SD}=$ $10.29)$ at the time of Grade 1.

\section{Measures}

Constructs, labels, instruments (original and modifications), number of items, and reliabilities of the measures are shown in the Appendix Table 2.

First, students were asked to write down the name of their first teachers. Students were matched with their teachers according to this report. Second, students had to rate each item with respect to this teacher. The four items for assessing students' perceptions of teacher emotional support were adapted from Perceptions of the classroom social environment questionnaire (Patrick et al. 2007; see also Authors 2016a). The items tapped the perceptions that a teacher cares about and likes the student as a person (e.g. 'The teacher respected your opinion'). Students had to use a 5-point Likert-type scale $(1-$ not at all correct; ....5absolutely correct).

The ECCOM (Stipek and Byler 2004) was used to assess child-centred and teacher-directed practices. The ECCOM has been translated and successfully adapted for use in Estonian educational settings (for adaptations of the ECCOM, see Authors 2017a). Both types of practices included 14 items that were rated on a 5-point scale based on the percentage of time each type of practice was visible during the observation: $1=$ the practice is rarely seen ( $0-20 \%$ of the time) to $5=$ the practice 
predominates (80-100\% of the time). Items tapped management (child responsibility, management, choice of activities, and disciplinary strategies), instruction (learning standards, coherence of instructional activities, teaching concepts, instructional conversation, literacy instruction, and math instruction), and climate (support for communication and interpersonal skills, student engagement, and individualization of learning activities). The exact wording of each item differed among types. For example, the Individualization of Learning Activities item was described as 'Teacher is attentive to children's individual skill levels and adapts tasks accordingly' (Child-Centred Practices) and 'Tasks are not flexible or adapted to children's individual needs' (Teacher-Directed Practices). Each teacher received two scores: one reflecting the mean of child-centred practices, and the other reflecting the mean of teacher-directed practices. As child-centred and teacher-directed practices were highly negatively correlated ( -.85 and -.78 , respectively, for Grades 1 and 3 ), the composite score of child-centred and reverse score of teacher-directed practices were also used, both of which have been used in earlier studies (Hauser-Cram, Sirin and Stipek 2003; Lerkkanen et al. 2012; Authors 2017b).

\section{Teacher-reported practices}

We created the Teacher-Reported Practices Scale (see Authors 2014) based on a prior questionnaire for parents. The questionnaire included three items for Affection (e.g. 'I encourage children to be independent/to do their best', 'I accept children's opinions'), three for Behavioural control (e.g. 'If needed, I punish children'), and three for Psychological control (e.g. 'I tell children how much I have done for them'). Teachers were instructed to think about the children they were teaching and to rate each question on a 5-point scale (1never, 5-always).

\section{Task-persistent learning behaviour}

Teachers assessed children's task persistence using the Behavioural Strategy Rating Scale (see Zhang et al. 2011 for the original scale and its validation). Teachers were first asked to think about and recall how a certain child typically behaved in a classroom learning situation, and then to rate the child's behaviour on a 5-point rating scale ( $1=$ not at all; $5=$ to a great extent). Two statements assessed the degree to which children were persistent (e.g. 'shows activity and persistence in activities and solving tasks'). Three items dealt with children's lack of persistence and task-irrelevant behaviours (e.g. 'easily loses his/her focus when the activity or task is not going well'). Before creating an average across the five statements, the three negatively worded items were reverse scored (maximum score $=5$ ).

\section{Data analysis}

Due to the nested nature of our data (i.e. students in the same classroom share one teacher), a multilevel modelling technique (Heck and Thomas 2015) was used to examine the classroomlevel correlations between students' perceived teacher emotional support and other teaching practices (i.e. observed teaching and teacher self-report teaching). For variables at the same data level, including both individual-level variables (e.g. students' perceived teacher emotional support and teacher rated each students' task persistence) and classroom-level variables (e.g. observed teaching and teacher self-report teaching), Pearson's $r$ was calculated to measure their correlations. 
Child-perceived teacher emotional support, its relations with teaching...

In addition, multilevel modelling was used to examine the joint influence of students' perceived teacher emotional support, observed teaching, and teacher self-report teaching practices on students' task persistence. For individual-level variables, intra-class correlations (ICC) were calculated in order to determine their proportion of variance due to classroom differences (between-classroom variation).

All analyses were performed using the Mplus statistical package (Version 8; Muthén and Muthén1998-2017). The standard missing-at-random (MAR) approach was applied (Muthén and Muthén1998-2017). The parameters of the models were estimated using FIML estimation with non-normality robust standard errors (MLR estimator; Muthén and Muthén1998-2017). For all models, goodness of fit was evaluated using four indicators: chi-square, Bentler's comparative fit index (CFI), the Tucker-Lewis index (TLI), and the root mean square error of approximation (RMSEA). According to Heck and Thomas (2015), CFI and TLI values above 0.95 and RMSEA values below 0.06 can be considered as indicators of good fit of the model to the data.

\section{Results}

\section{Correlations among three measures}

Descriptive statistics and correlations among the study variables are shown in Table 1. Since was listed out to show more depth correlations between students' perceived emotional support and observed teaching practices. As shown in Table 1, although Grade 1 observed childcentred practices (OCC1), teacher-directed practices (OTD1), and their Climate subscales (OCC-CL1 and OTD-CL1, respectively) did not correlate with students' perceived emotional OCC1 and its climate positively, and with OTD1 and its climate negatively. In addition, SPE demonstrated a significant negative correlation with teacher-reported psychological control in Grade 1 (TPC $1 ; r=-.50, p<.001)$.

At third grade, SPE had a significant positive correlation with child-centred practices' climate (OCC-CL3; $r=.35, p<.05$ ) and a significant negative correlation with teacherdirected practices (OTD1; $r=-.44, p<.01$ ) and its climate (OTD-CL3; $r=-.48, p<.01$ ). However, no significant correlations were found between SPE and teacher-reported affection, behaviour control, or psychological control.

\section{The joint influences of three measures on task persistence}

One of the research aims was to examine the unique contribution of each measure to students' learning behaviour. Multilevel modelling was utilised to account for the nested nature of our study variables and to include all study variables together. First, intra-class correlations (ICC) were calculated for SPE and task persistence in Grades 1 and 3 (TP1 and TP3). All were significant $(.22, .14, .08$, respectively, for SPE, TP1, TP3; all $p<.01)$ and thus were analysed at both the between and within levels. Second, since child-centred practices and teacher-directed practices were highly related, a composite score was used so that multicollinearity effects could be reduced (Dormann et al. 2013).

Two separate models were run for data from Grades 1 and 3, respectively (see Figs. 1 and 2). In 


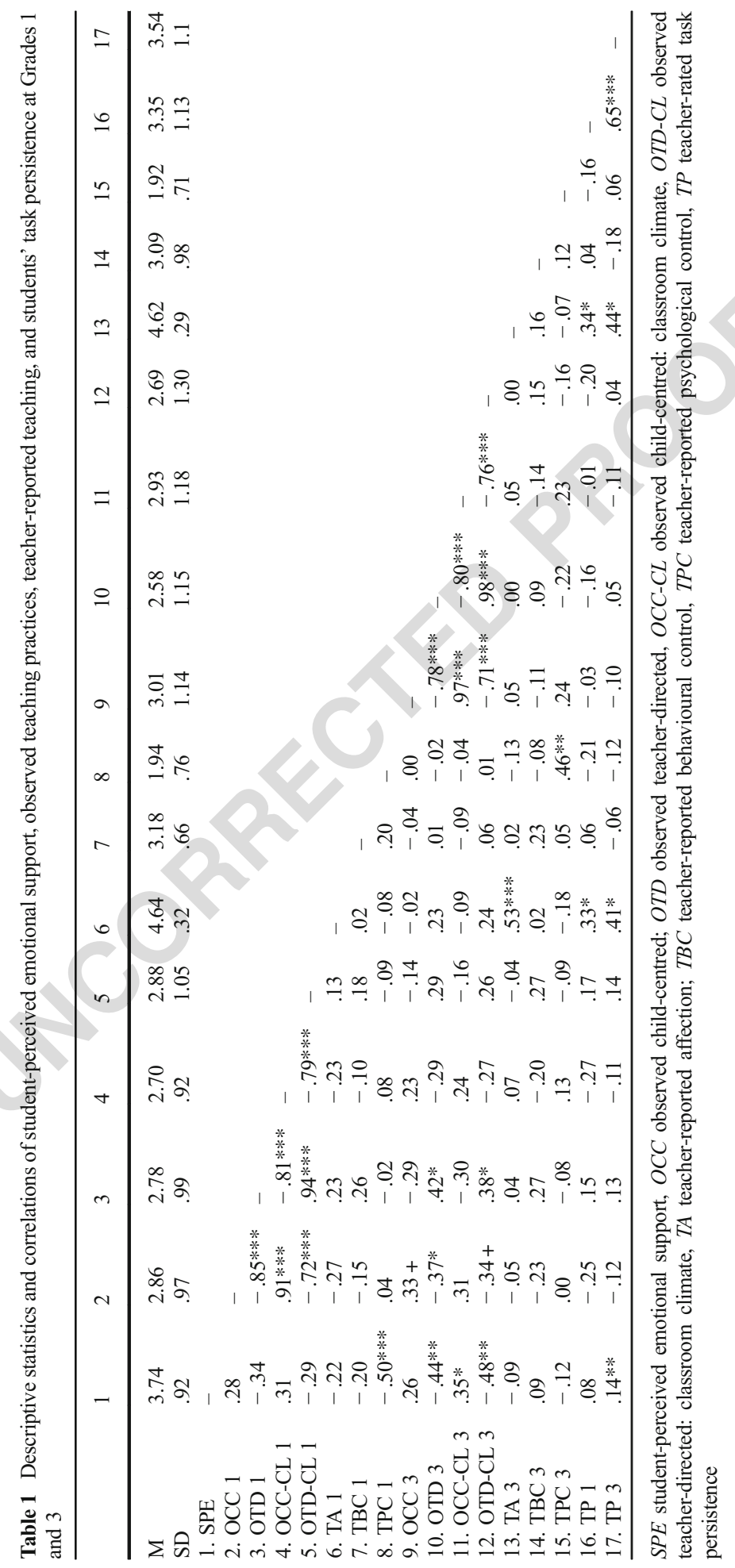


Child-perceived teacher emotional support, its relations with teaching...

RMSEA $=0$ ), which indicated a perfect fit for the model (Heck and Thomas 2015). The results the composite score of child-centred and teacher-directed practices (OCC-TD1) was found to be negatively correlated with teacher-reported behaviour control (TBC1) $(r=-.27, p<.05)$. Moreover, the $R^{2}$ showed that the classroom-level predictors (i.e. SPE, OCC-TD1, TA1, TBC1, and TPC1) explained $16.9 \%$ of the variance of TP1, whereas the individual-level predictor (i.e. SPE) explained only $1.2 \%$ of the variance.

In Grade 3, the model was also just-identified and indicated a perfect fit for the model. $(\beta=.56, p<.01)$. However, the role of TBC3 and TPC3 on TP3 was showed to be marginally significant. At the individual level, SPE positively associated with TP $3(\beta=.18, p<.001)$. Moreover, the results showed that OCC-TD3 correlated with SPE positively at classroom level $(r=.43, p<.01)$. In addition, the $R^{2}$ showed that the classroom-level predictors (i.e. SPE, OCC-TD3, TA3, TBC3, and TPC3) explained $38.7 \%$ variance of TP3, whereas individuallevel predictor (i.e. SPE) explained $3.1 \%$ variance.

\section{Discussion}

Experiencing emotional support from teachers creates a context where students feel safe, dare to try new things, exert effort, and engage in learning. Thus, emotional support from teachers is acknowledged as an important source of student development and learning. Although it is

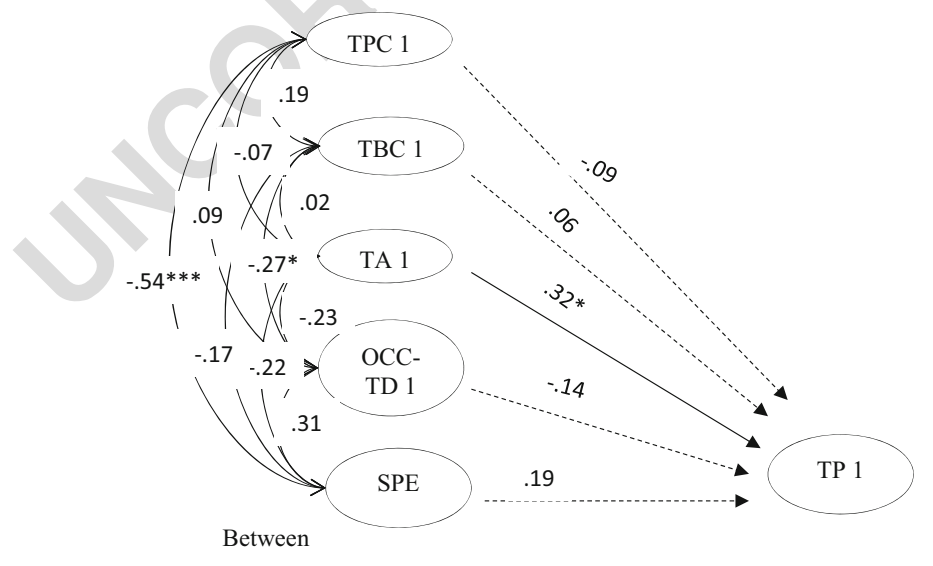

Within

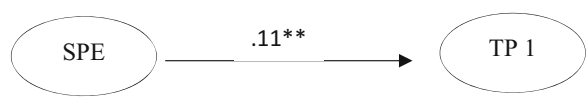

Fig. 1 The joint contribution of student-perceived emotional support, observed teaching, and self-reported teaching on task persistence in grade 1. SPE, student-perceived emotional support; OCC-TD, composite score of observed child-centred and teacher-directed; TA, teacher-reported affection; TBC teacher-reported behavioural control; TPC, teacher-reported psychological control; TP, teacher-rated task persistence 


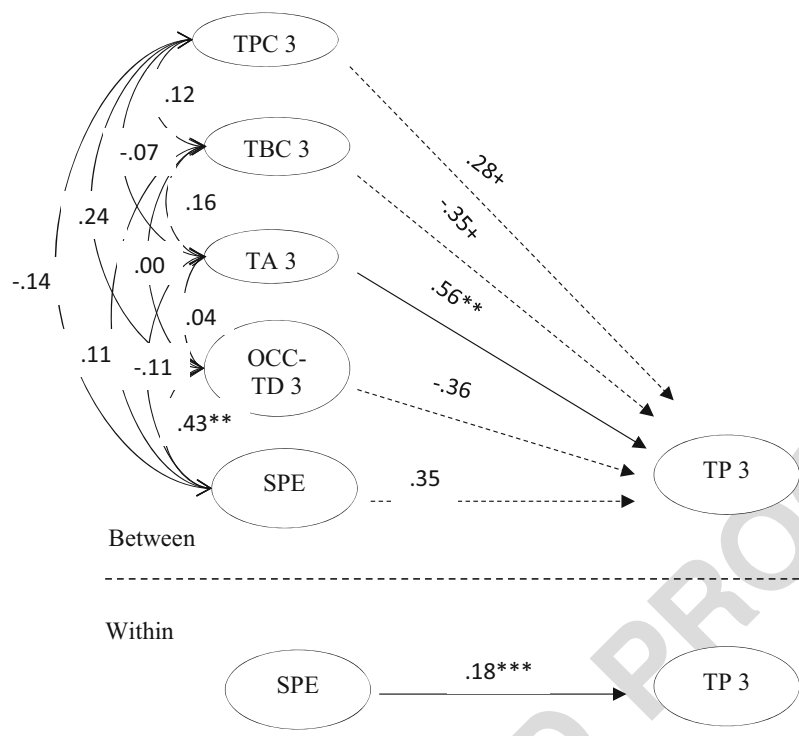

Fig. 2 The joint contribution of student-perceived emotional support, observed teaching, and self-reported teaching on task persistence in grade 3. SPE, student-perceived emotional support; OCC-TD, composite score of observed child-centred and teacher-directed; TA, teacher-reported affection; TBC, teacher-reported behavioural control; TPC, teacher-reported psychological control; TP, teacher-rated task persistence

expected that some teaching practices put more emphasis on emotional support than others, only a few studies have explicitly studied relations between general teaching practices and student-perceived support. Our study aimed to examine relations between observed and teacher-reported teaching practices and students' perceived emotional support during the first years of school. Retrospective student-reported teacher emotional support tended to be positively related to child-centred and negatively to teacher-directed practices as observed by the observational tool ECCOM in Grade 3, and it was also negatively related to teacher-reported psychological control in Grade 1. While higher perceived emotional support was related with more persistent learning behaviour on an individual level, general task persistence was predicted mainly by teacher-reported practices at the classroom level.

\section{Perceived emotional support and teaching practices}

When using sixth graders' reports of their first teacher's emotional support, it was expected that students would remember how positive, caring, and respectful the classroom atmosphere had been, and how sensitive to their needs and interests teachers had been (Hamre and Pianta 2010; Patrick et al. 2007). Although students had been taught by the same teacher first 3 years in school, teachers might change their general teaching practices and individualised support for each student during these years. Teachers engage in teaching practices, taking into account the specifics of learnt to be material and also skill level of students in the classroom (Authors 2018). Thus, relations between student reports and teacher practices in first and third grades were examined, with expectations that relations would be higher for Grade 3 as children might remember better the later practices. According to ECCOM, child-centred and teacher-directed practices are observed separately; however, the scores are highly negatively related - the more teacher uses one type of practices, the less she applies the others. Both separate and combined 
Child-perceived teacher emotional support, its relations with teaching...

scores were used (Hauser-Cram et al. 2003; Lerkkanen et al. 2012; Authors 2017b) and also separate climate subscale score (see Authors 2017a). As expected, students retrospectively perceived higher emotional teacher support when teachers applied teacher-directed practices less frequently as compared to child-centred practices in Grade 3. Teacher-directed practices are directed to acquiring basic academic skills with teacher's initiative and teacher-provided tasks while students are regarded as passive 'receivers' (Gettinger and Kohler 2011; Woolfolk Hoy and Weinstein 2011). Thus, students may experience control and demands rather than support from teachers during these practices. This may be one of the reasons why students in teacher-directed classrooms tend to have lower motivation for learning and lower levels of interest (Authors 2018; Lerkkanen et al. 2012; Perry et al. 2007). Typically, only general ECCOM scales are used, but three subscales are separate in the original: management, instruction, and climate (Stipek and Byler 2004). In a validation study, Authors (2017a) also differentiated these subscales, but they also showed that relations among subscales were very high. The findings of this study indicate that emotional support was a bit better tapped by the climate subscale, thus this subscale may be more appropriate to use when analysing the emotional development of children.

Teacher reports on their practices have been used similarly to parental reports (Dever and Karabenick 2011; Kiuru et al. 2012; Authors 2016b; Walker 2008). It was found that students' perceived emotional support was only negatively related to teacher-reported psychological control in Grade 1, but not related to other teacher-reported practices. It might be expected that teachers with high affection are perceived as emotionally supportive. That it was not found may be related to biased teacher reports somehow - due to social desirability, teachers may report to be more caring. It is also possible that even a few humiliating comments referring to guilt or shame may trigger negative experiences that children remember more than daily caring expressions. Similarly, earlier studies have shown a strong negative effect of psychological control on child development (Barber 1996; Soenens et al. 2012; Soenens and Vansteenkiste 2010). In addition, teachers with high psychological control may create an environment where children feel insecure and their basic needs for relatedness not satisfied (Assor et al. 2005; van der Kaap-Deeder et al. 2017). It can only be hypothesised why relations with psychological control were visible only in Grade 1 and not in Grade 3. It may be that teacher behaviours like affection withdrawal, inducing guilt, and shame are perceived as especially harmful when students are younger. In addition, children may get used to these practices with time and thus do not perceive them as especially unpleasant later on in life.

\section{Emotional support, teacher practices, and task persistence}

Since, as expected, modest correlations were found between students' perceived emotional support, observed teaching practices, and self-reported teaching practices, it was of interest and importance to examine each measures' unique contribution to students' learning behaviour. Expected relations on an individual level in both grades were uncovered - students who reported higher teacher emotional support were marked by teachers as being more task persistent than those who perceived emotional support as lower. Teachers support students' interest and motivation when giving tasks that are meaningful and in accordance with student's skill level. Emotionally supportive teachers may be more perceptive both of a child's interests and difficulties, and thus select adequate tasks which raise the student's interest and support their engagement (Klem and Connell 2004; Patrick et al. 2007; 
also elicit positive behaviours from children, as the children strive to please their teacher. Earlier empirical research has referred to the supportive effect of emotional support on students' behaviour, achievement, and motivation (Klem and Connell 2004; Patrick et al. 2007; Roorda et al. 2011).

Classrooms also varied in general perceived teacher support and teacher-reported task persistence. Still, the relation between emotional support and classroom-level task persistence was not significant. It may be that individualised practices related to specific students (Göllner et al. 2017; Hamre and Pianta 2010) may play a different role on student's perceived emotional support and his/ her behaviour. Surprisingly, only teacher-reported affection had a positive effect on classroom-level students' task persistence in both grades. In other words, teachers who rated themselves as more supportive and kind towards students also rated the students as more task persistent in challenging situations. One reason of this finding may be related to the way students' task persistence was assessed - with teacher reports. Thus, teacher beliefs might influence both their self-ratings of teaching practices and ratings of students' task-persistent learning behaviour. Still, in another study that examined the teacher-reported affection and student-rated task persistence in Grades 1 to 3, teacher-reported affection was shown to have a positive influence on children-reported task persistence (Kiuru et al. 2014). The finding that observed practices were not related to classroomlevel task persistence was also unexpected. In an earlier study, observed child-centred practices were found to be related to student-reported interest (that is, related to persistence) in Grade 1 (Authors 2018). However, Authors (2014) showed that the positive effect of child-centred practices depends on classroom peer context. Namely, the positive effect of child-centred practices was visible only in classrooms where general initial persistence was high, while teacher-directed practices were of benefit in classrooms with low persistence. Thus, the null findings may be related both to the way students' learning behaviour was assessed (with teacher reports, not students' reports or observations) and to different classroom contexts, the roles of which were not examined.

\section{Limitations and future directions}

Some limitations of the study should also be taken into account. First, the number of participating teachers and classrooms was relatively small. Second, retrospective reports were used for teacher emotional support, and student perceptions can change over time due to new school experiences.

Retrospective reports were used due to difficulties in collecting young students' opinions (Roorda et al. 2011). Still, future studies should use other methods (e.g. interviews) to tap primary school students' perceptions of their teachers. Third, the study was carried out in Estonia, where one teacher teaches almost all lessons during the first 3 years of schooling. This creates a situation in which students may remember teacher behaviour better than in schools where teachers change each year. Thus, in countries like Estonia, the effects of teacher practices may be more visible but also more important for students' later achievements and well-being. Similar studies should also be carried out in other cultural contexts. Fourth, the peer context of the classroom was not taken into account, and this could alter findings. In the future, studies should be carried out with more classrooms that examine both teacher practices and classroom contexts, and their interactive effects on student perceptions and behaviour. Fifth, the present study discovered a significant association between teacher-reported affection and teacher-rated students' task persistence in both grades. This result should be interpreted with caution, however, because both variables were reported by the teacher, and the possible single-reporter effect may explain these associations. Still, it is interesting to note that, as opposed to teacher affection, teacher-reported psychological and behaviour control 
Child-perceived teacher emotional support, its relations with teaching...

explain students' task persistence. This may due to other variables which were not examined. For example, task persistence has been found to be affected by classroom motivational climate (Ames 1992) and goal structure (Meece, Anderman and Anderman 2006). It is important for future studies to include these variables as predictors for task persistence.

Funding information This work received financial supported by the Estonian Ministry of Education and Research (grant no. IUT 03-03).

\section{Compliance with ethical standards}

Conflict of interest The authors declare that they have no conflicts of interest.

\section{Appendix}

Table 2 Constructs, labels, instruments, number of items, and reliabilities of the measures

\begin{tabular}{|c|c|c|c|c|}
\hline Construct & Label & Instrument & $\begin{array}{l}\text { No. } \\
\text { of } \\
\text { items }\end{array}$ & $\begin{array}{l}\text { Cronbach's } \\
\text { alpha }\end{array}$ \\
\hline
\end{tabular}
teacher emotional support

\section{t2.4 Observed child-centred} practices at Grade 1/Grade3

Observed teacher-directed practices at Grade1/Grade3

Classroom climate in observed child-centred practices at Grade1/Grade3

Classroom climate in observed teacher-directed practices at Grade 1/Grade3

Composite score of observed child-centred and teacherdirected practices at Grade 1/Grade3

Teacher-reported affection at Grade 1/Grade3

Teacher-reported behavioural control at Grade 1/Grade3 control at Grade 1/Grade3

Teacher-rated students' task
Students' perceptions of

\section{SPE}

Perceptions of the classroom social environment questionnaire (adapted from Patrick et al. 2007; Authors 2016)

\section{OCC1/OCC3}

OTD1/OTD3

Teacher-reported psychological persistence at Grade1/Grade3
OCC-CL1/OCC-CL3 ECCOM

OTD-CL1/
OTD-CL 3

ECCOM

OCC-TD1/OCC-TD3 ECCOM
TA1/TA3

TBC1/TBC3

TPC1/TPC3

TP1/TP3
Teacher-Reported Practices Scale (TRPS; Authors 2015) TRPS

TRPS

Behavioural Strategy Rating Scale (see Zhang et al. 2011 for the original scale and its validation)

\section{$.91 / .95$}




\section{References}

Ames, C. (1992). Classrooms: Goals, structures, and student motivation. Journal of Educational Psychology, 84(3), 261-271.

Archambault, I., Pagani, L. S., \& Fitzpatrick, C. (2013). Transactional associations between classroom engagement and relations with teachers from first through fourth grade. Learning and Instruction, 23, 1-9.

Assor, A., Kaplan, H., Kanat-Maymon, Y., \& Roth, G. (2005). Directly controlling teacher behaviors as predictors of poor motivation and engagement in girls and boys: The role of anger and anxiety. Learning and Instruction, 15(5), 397-413.

Authors (2014).

Authors (2016a).

Authors (2016b).

Authors (2017a).

Authors (2017b).

Authors (2018).

Bandura, A. (1993). Perceived self-efficacy in cognitive development and functioning. Educational Psychologist, 28(2), 117-148.

Barber, B. K. (1996). Parental psychological control: Revisiting a neglected construct. Child Development, 67(6), 3296-3319.

Baumrind, D. (1967). Effects of authoritative parental control on child behavior. Child Development, 37, 887907.

Curby, T. W., Rimm-Kaufman, S. E., \& Ponitz, C. C. (2009). Teacher-child interactions and children's achievement trajectories across kindergarten and first grade. Journal of Educational Psychology, 101(4), 912-925.

Deci, E., \& Ryan, R. (2000). The "what" and "why" of goals pursuits: human needs and the self-determination of behavior. Psychological Inquiry, 11(4), 227-268.

Dever, B. V., \& Karabenick, S. A. (2011). Is authoritative teaching beneficial for all students? A multi-level model of the effects of teaching style on interest and achievement. School Psychology Quarterly, 26(2), 131-144.

Dormann, C. F., Elith, J., Bacher, S., Buchmann, C., Carl, G., Carré, G., et al. (2013). Collinearity: a review of methods to deal with it and a simulation study evaluating their performance. Ecography, 36(1), $27-46$.

Downer, J., Stuhlman, M., Schweig, J., Martinez, J., \& Ruzek, E. (2016). Measuring effective teacher-student interactions from a student perspective: A multi-level analysis. Journal of Early Adolescence, 35, 722-758.

Gettinger, M., \& Kohler, K. (2011). Process-outcome approaches to classroom management and effective teaching. In C. Evertson \& C. Weinstein (Eds.), Handbook of classroom management. Research, practice, and contemporary issues (pp. 73-95). New York, NY: Routledge.

Göllner, R., Wagner, W., Eccles, J., \& Trautwein, U. (2017). Students' idiosyncratic perceptions of teaching quality in mathematics: a result of rater tendency alone or an expression of dyadic effects between students and teachers? Journal of Educational Psychology.

Grolnick, W. S., Ryan, R. M., \& Deci, E. (1991). Inner resources for school achievement: motivational mediators of children's perceptions of their parents. Journal of Educational Psychology, 83(4), 508-517.

Hamre, B., \& Pianta, R. (2010). Classroom environments and developmental processes: Conceptualization and measurement. In J. Meece \& J. Eccles (Eds.), Handbook of research on schools, schooling, and human development (pp. 25-41). New York, NY: Routledge.

Hauser-Cram, P., Sirin, S. R., \& Stipek, D. (2003). When teachers' and parents' values differ: teachers' ratings of academic competence in children fromlow-income families. Journal of Educational Psychology, 95(4), 813-820.

Heck, R. H., \& Thomas, S. L. (2015). Quantitative methodology series. An introduction to multilevel modeling techniques: MLM and SEM approaches using Mplus (3rd ed.). New York: Routledge/Taylor \& Francis Group.

Kiuru, N., Aunola, K., Torppa, M., Lerkkanen, M. -K., Poikkeus, A. -M., Niemi, P., et al. (2012). The role of parenting styles and teacher interactional styles in children's reading and spelling development. Journal of School Psychology, 50(6), 799-823.

Kiuru, N., Pakarinen, E., Vasalampi, K., Silinskas, G., Aunola, K., Poikkeus, A. M., et al. (2014). Task-focused behavior mediates the associations between supportive interpersonal environments and students' academic performance. Psychological Science, 25(4), 1018-1024.

Klem, A. M., \& Connell, J. P. (2004). Relationships matter: linking teacher support to student engagement and achievement. Journal of School Health, 74(7), 262-273.

Lerkkanen, M. -K., Kiuru, N., Pakarinen, E., Viljanranta, J., Poikkeus, A. -M., Rasku-Puttonen, H., et al. (2012). The role of teaching practices in the development of children's interest in reading and mathematics in kindergarten. Contemporary Educational Psychology, 37(4), 266-279. 
Child-perceived teacher emotional support, its relations with teaching...

McCombs, B. (2010). Learner-centered practices: Providing the context for positive learner development, motivation, and achievement. In J. Meece \& J. Eccles (Eds.), Handbook of research on schools, schooling, and human development (pp. 60-74). New York, NY: Routledge.

Meece, J. L., Anderman, E. M., \& Anderman, L. H. (2006). Classroom goal structure, student motivation, and academic achievement. Annual Review of Psychology, 57(1), 487-503.

Muthén, L. K., \& Muthén, B. O. (1998-2017). Mplus User's Guide (Eighth ed.). Los Angeles, CA: Muthén \& Muthén.

Patrick, H., Kaplan, A., \& Ryan, A. (2007). Early adolescents' perceptions of the classroom social environment, motivational beliefs, and engagement. Journal of Educational Psychology, 99(1), 83-98.

Patrick, H., Kaplan, A., \& Ryan, A. M. (2011). Positive classroom motivational environments: convergence between mastery goal structure and classroom social climate. Journal of Educational Psychology, 103(2), $367-382$.

Perry, K., Donohue, K., \& Weinstein, R. (2007). Teaching practices and the promotion of achievement and adjustment in first grade. Journal of School Psychology, 45(3), 269-292.

Pianta, R. C., Belsky, J., Vandergrift, N., Houts, R., Morrison, F., \& The NICHD Early Child Care Research Network. (2008). Classroom effects on children's achievement trajectories in elementary school. American Educational Research Journal, 45, 365--397.

Roorda, L., Koomen, H., Spilt, J., \& Oort, F. (2011). The influence of affective teacher-student relationships on students' school engagement and achievement: a meta-analytic approach. Review of Educational Research, 81(4), 493-529.

Salminen, J., Lerkkanen, M. K., Poikkeus, A. M., Pakarinen, E., Siekkinen, M., Hännikäinen, M., et al. (2012). Observed classroom quality profiles of kindergarten classrooms in Finland. Early Education \& Development, 23, 654-677.

Skinner, E. A., \& Belmont, M. J. (1993). Motivation in the classroom: reciprocal effects of teacher behavior and student engagement across the school year. Journal of Educational Psychology, 85, 571-581.

Soenens, B., \& Vansteenkiste, M. (2010). A theoretical upgrade of the concept of parental psychological control: Proposing new insights on the basis of self-determination theory. Developmental Review, 30(1), 74-99.

Soenens, B., Sierens, E., Vansteenkiste, M., Dochy, F., \& Goossens, L. (2012). Psychologically controlling teaching: examining outcomes, antecedents, and mediators. Journal of Educational Psychology, 104(1), $108-120$.

Stipek, D., \& Byler, P. (2004). The early childhood classroom observation measure. Early Childhood Research Quarterly, 19(3), 375-397.

Turner, J. C., Midgley, C., Meyer, D. K., Gheen, M., Anderman, E. M., Yongjin, K., et al. (2002). The classroom environment and students' reports of avoidance strategies in mathematics: a multimethod study. Journal of Educational Psychology, 94(1), 88-106.

Van der Kaap-Deeder, J., Vansteenkiste, M., Soenens, B., \& Mabbe, E. (2017). Children's daily well-being: The role of mothers', teachers', and siblings' autonomy support and psychological control. Developmental Psychology, 53, 237-251.

Walker, J. M. T. (2008). Looking at teacher practices through the lens of parenting style. The Journal of Experimental Education, 76(2), 218-240.

Woolfolk Hoy, A., \& Weinstein, C. (2011). Student and teacher perspectives on classroom management. In C. Evertson \& C. Weinstein (Eds.), Handbook of classroom management. Research, practice, and contemporary issues (pp. 181-219). New York: Routledge.

Yen, K., Konold, T., \& McDermott, P. (2004). Does learning behavior augment cognitive ability as an indicator of academic achievement? Journal of School Psychology, 42(2), 157-169.

Zhang, X., Nurmi, J. -E., Kiuru, N., Lerkkanen, M. -K., \& Aunola, K. (2011). A teacher report measure of children's task-avoidant behavior: a validation study of the Behavioral Strategy Rating Scale. Learning and Individual Differences, 21(6), 690-698.

Eve Kikas. School of Natural Sciences and Health, Tallinn University, Narva mnt. 25, 10120 Tallinn, Estonia; Email: eve.kikas@tlu.ee

Current themes of research:

Children's development and learning in kindergarten and school. The role of individual characteristics and contextual factors (e.g. teaching practices, parental support) in students' learning, considering varying skill levels and ages. 
Most relevant publications in the field of Psychology of Education:

Peets, K., \& Kikas, E. (2017). Teachers' promotion or inhibition of children's aggression depends on peer-group characteristics. Journal of Clinical Child \& Adolescent Psychology, 46, 848-857. DOI: https://doi. org/10.1080/15374416.2015.1079778

Kikas, E., Pakarinen, E., Soodla, P., Peets, K., \& Lerkkanen, M.-K. (2017). Associations between reading skills, interest in reading, and teaching practices in first grade. Scandinavian Journal of Educational Research. DOI:https://doi.org/10.1080/00313831.2017.1307272

Kikas, E., Silinskas, G., Jõgi, A.-L., \& Soodla, P. (2016). Effects of teacher's individualized support on children's reading skills and interest in classrooms with different teaching styles. Learning and Individual Differences, 49, 270-277. Doi: https://doi.org/10.1016/j.lindif.2016.05.015

Kikas, E., \& Mägi, K. (2016). Does self-efficacy mediate the effect of primary school teachers' emotional support on learning behavior and academic skills? Journal of Early Adolescence, 37, 696-730. doi: https://doi. org $/ 10.1177 / 0272431615624567$

Kikas, E., Silinskas, G., and Soodla, P. (2015). The effects of children's reading skills and interest on teacher perceptions of children's skills and ndividualized support. International Journal of Behavioral Development, 39, 402-412. DOI: https://doi.org/10.1177/0165025415573641.

Kikas, E., Peets, K., and Hodges, E. (2014). Collective student characteristics alter the effects of teaching practices on academic outcomes. Journal of Applied Developmental Psychology, 35, 273-283.

Kikas, E. (2004). Teachers' conceptions and misconceptions concerning three natural phenomena. Journal of Research in Science Teaching, 41, 432-448.

Xin Tang. Department of Educational Science, University of Helsinki, Finland; E-mail: xin.tang@ @elsinki.fi

Current themes of research:

Teaching practices. Reading development. Motivation and engagement.

Tang, X., Pakarinen, E., Lerkkanen, M.-K., Kikas, E., Muotka, J., \& Nurmi, J.-E. (2017). Validating the early childhood classroom observation measure in first and third grade classrooms. Scandinavian Journal of Educational Research, 61, 275-294.

Tang, X., Kikas, E., Pakarinen, E., Lerkkanen, M.-K., Muotka, J., \& Nurmi, J.-E. (2017). Profiles of teaching 


\section{AUTHOR QUERIES}

\section{AUTHOR PLEASE ANSWER ALL QUERIES.}

Q1. Please check if the affiliation 2 address is presented/captured correctly.

Q2. Please check if Tables 1 to 2 entries and legends are captured/ presented correctly.

Q3. Please check if Figures 1 and 2 captions are captured correctly.

Q4. Reference [Muthén \& Muthén, 1998-2017] was provided in the reference list; however, this was not mentioned or cited in the manuscript. As a rule, all references given in the list of references should be cited in the main body. Please provide its citation in the body text.

Q5. Please check added information in the reference list (issue number) if correct. Thank you.

Q6. Please provide complete details for references Authors 2014, 2016a,b, 2017a,b, 2018. 